\title{
Rock My World: Rewind to a Better Transition to Remote Learning
}

\author{
Michelle E. Garland ${ }^{1 *}$ and Michelle T. Violanti ${ }^{2}$ \\ ${ }^{1}$ Center for Interdisciplinary Studies/Division of Fine Arts and Communication Studies, University of South Carolina Upstate, \\ Spartanburg, SC, United States, ${ }^{2}$ School of Communication Studies, The University of Tennessee Knoxville, Knoxville, TN, \\ United States
}

\section{OPEN ACCESS}

Edited by:

Tatiana M. Permyakova, National Research University Higher School of Economics, Russia

Reviewed by:

Elena Smolianina, National Research University Higher

School of Economics, Russia Paromita Pain,

University of Nevada, United States

${ }^{*}$ Correspondence:

Michelle E. Garland mgarlan2@uscupstate.edu

Specialty section: This article was submitted to Culture and Communication, a section of the journal Frontiers in Communication

Received: 15 December 2020 Accepted: 22 January 2021 Published: 22 February 2021

Citation: Garland ME and Violanti MT (2021) Rock My World: Rewind to a Better

Transition to Remote Learning.

Front. Commun. 6:641873. doi: $10.3389 /$ fcomm.2021.641873
Students and faculty alike found themselves in tumultuous times as they made the transition from face-to-face to remote learning. As faculty and administrators worked hard to overcommunicate with students in the hopes of keeping them engaged and focused on their academic pursuits, students found their attentions split among school, the Covid-19 health pandemic, and paying bills as many lost their employment. In some cases, the overcommunication led to students ignoring messages as they were completely overwhelmed; at the same time, some students found themselves reverting back to looking for the days of someone telling them what to do every minute of the day. Because faculty, and administrators, were not well prepared to handle the situation, an unevenness in how faculty communicated with students occurred. That is, some faculty withdrew in the same way that students did, and the term essentially ended with students turning in remaining assignments even though no further instruction occurred. Other faculty tried to move their face-to-face class online without taking into consideration the differences between these two channels. Still others tried to create an online course as they went from week to week. The inconsistencies across classes combined with the additional stress students were already experiencing became a recipe for exactly what the administration was trying to avoid-unsuccessful completion of courses and/or students unprepared for the courses that would come after the ones in which they were enrolled that term. The purpose of this study is to examine the experiences and perceptions of students when their classes pivoted from face-to-face to mediated, usually through video conferencing for synchronous or learning management systems for asynchronous. More specifically, we have collected qualitative data that addresses the communication students received from their instructors, what they believed instructors did successfully, what instructors could have done better, and the advice they would offer to instructors who found themselves in a similar crisis situation in the future.

Keywords: COVID-19, remote learning, instructional communication, uncertainty management, expectancy violations 
Uncertainty. Few, if any words, better describe the universal feeling associated with education during the COVID-19 pandemic. The pivot term of 2020 resulted in a cataclysm for institutions of higher education as faculty and students in a classroom instructional setting were forced to shift to a remote environment almost overnight. Students and faculty alike found themselves in tumultuous times as they transitioned from face-toface to remote learning. ${ }^{1}$ For some higher education institutions, spring break was extended for a week or two to allow faculty to adjust their courses to the new environment. For others, the term timeline did not change, and the adjustment was more rushed. Regardless, the shift was unexpected, abrupt, and allowed for little adjustment period. Faculty, regardless of training or experience, were forced to create course content, assignments, and other learning experiences to fit the new format. As such, faculty were often adapting as the term progressed. According to a May The Chronicle survey 2020, "about $60 \%$ of faculty members, and a similar share of academic administrators, said that the spring's courses were worse than their face-to-cate counterparts."

Because faculty, and administrators, were not well prepared to handle the situation, an unevenness in how faculty communicated with students occurred. That is, some faculty withdrew in the same way that students did, and the term essentially ended with students turning in remaining assignments even though no further instruction occurred. Other faculty tried to move their face-to-face class online without taking into consideration the differences between these two channels. Still others tried to create a remote course as they went from week to week. These inconsistencies across classes combined with the additional stress students were already experiencing became a recipe for exactly what the administration was trying to avoid-unsuccessful completion of courses and/or students unprepared for the courses that would come after the ones in which they were enrolled that term. Furthermore, due to COVID-19, one study found that $13 \%$ of students delayed graduation and $40 \%$ of students lost a job, internship, or other offer (Aucejo, et al., 2020).

Despite what institution administrators were doing to support faculty and students during this transition, the COVID-19 pandemic caused an unparalleled upheaval with regard to the educational experience. The destruction from this cataclysmic event will be felt for some time, and long-lasting effects can be expected. Students, in particular, were heavily impacted by the pandemic personally, professionally, and academically. "Uncertainty, instability, and self-doubt have been common themes in the lives of college students during 2020 as their education and career plans shift due to the coronavirus pandemic" (Inside Higher Education, 2020; par. 2). Moreover.

- $80 \%$ of college students report that COVID-19 has negatively impacted their mental health;

\footnotetext{
${ }^{1}$ Note that the term online learning has not been used here because there is a distinct difference between using an online platform to deliver what would have been face-to-face content and developing a course where the online platform and student characteristics are an integral part of the design process.
}

- $91 \%$ of the $80 \%$ report stress and anxiety;

- $81 \%$ of the $80 \%$ report disappointment and sadness;

- $80 \%$ of the $80 \%$ report loneliness or isolation;

- $48 \%$ of the $80 \%$ report financial setback;

- $56 \%$ of the $80 \%$ report relocation;

- $76 \%$ of the $80 \%$ report having trouble keeping a routine;

- $63 \%$ of the $80 \%$ report finding it challenging to stay connected with others;

- $85 \%$ of the $80 \%$ report focusing on school and work despite the distractions have been the most difficult thing about stay-at-home order (Active Minds, 2020).

As faculty and administrators worked hard to overcommunicate with students in the hopes of keeping them engaged and focused on their academic pursuits, students found their attentions split among school, the COVID-19 health pandemic, and paying bills as many lost their employment. In some cases, the overcommunication led to students ignoring messages as they were completely overwhelmed; at the same time, some students found themselves reverting back to looking for the days of someone telling them what to do every minute of the day.

While it is unlikely a worldwide event like the 2020 pandemic will happen again in the near future, there is much that can be learned about how students and faculty react to an abrupt educational shift, specifically with respect to communication behaviors, which include the various ways people exchange meaningful verbal and nonverbal messages. The purpose of this study is to examine the experiences and perceptions of students when their classes pivoted from face-toface to mediated, usually through video conferencing for synchronous or learning management systems for asynchronous. More specifically, we have collected qualitative data that address the communication students received from their instructors, what they believed instructors did successfully, what instructors could have done better, and the advice they would offer to instructors who find themselves in a similar crisis situation in the future.

\section{UNCERTAINTY MANAGEMENT}

Uncertainty has been a key word for 2020 in all aspects of life and was heightened in the transition of the learning environment during the pivot term as face-to-face courses were moved online abruptly, with little or no preparation. "Uncertainty exists when details of situations are ambiguous, complex, unpredictable, or probabilistic; when information is unavailable or inconsistent and when people feel insecure in their own state of knowledge," (Brashers, 2001, p. 478). Based on past research, student uncertainty is known to decrease over the course of the term, (e.g. Prisbell, 1990). However, the pivot term of 2020 disrupted the expected progression of uncertainty reduction. Uncertainty reduction is important in instruction in "normal" times (Goodboy \& Myers, 2007), so it can be assumed that uncertainty reduction is even more critical in times such as the COVID-19 pandemic. 
Uncertainty Reduction Theory, while in its conception (Berger \& Calabrese, 1975), explored processes associated with thoughts and behaviors as people initiate new relationships, the concept of uncertainty reduction has been applied in a broader context, though limitedly in instructional contexts (Goodboy \& Myers, 2007; Hanson, et al., 2014; Prisbell, 1990). At its core, uncertainty reduction theory is based on eight key concepts, from which axioms were developed: verbal communication, nonverbal warmth, information seeking, self-disclosure, reciprocity, similarity, liking, and shared networks. While intimacy, reciprocity, similarity, and liking are not anticipated to be central to the student experience during the transition to remote learning, verbal communication, nonverbal warmth, information seeking, and shared networks are expected to be prevalent in student experiences. Moreover, while nonverbal warmth may not be exemplified in the traditional sense, nonverbal warmth as expressed through computer-mediated contexts, are anticipated. Such expressions might include the use of emoticons, memes, or GIFs or providing a cell phone number so students can text questions. These expressions are more informal and personal in nature, suggesting nonverbal warmth.

Anyone involved in education during the 2020 pivot term is well aware of the challenges faced by stakeholders, regardless of position, experience, etc. Arguably, faculty and students felt the impact of this sudden shift more strongly than anyone else. Faculty and students were asking, "what now?" "Reducing uncertainty to an acceptable level is necessary for smooth, coordinated, and understandable interactions to occur and for individuals to have a sense of control over their environment and outcomes" (Goldsmith, 2001, p. 515). With this in mind, it seems teacher effectiveness during the transition to remote learning would require enhanced communication in terms of higher quality messages, a greater quantity of messages, and use of multiple channels to convey messages. Such communication would be expected to lead to students feeling comfortable and confident with the course and the teacher during the transition. Communication satisfaction has been identified as another outcome of uncertainty reduction, which resulted in a ninth axiom (Neuliep \& Grohskopf, 2000). While uncertainty plays a large role in adjusting to new and unique situations, closely aligned to such processes is the role of expectations.

\section{EXPECTANCY VIOLATIONS}

Expectations are a typical framework for making sense of new and unique situations. In the instructional context, both teacher and student expectations are taken into account. However, for the purpose of this study, the focus is on student expectations. When students enter a class for the first time, they bring with them expectations based on previous classroom experiences (Houser, 2005; Violanti, 2020). As the course progresses, student frameworks change and expectations are shifted. Those expectations are placed on course processes and procedures as well as teacher communication.
What happens, though, when no previous experiences can provide a framework for what to expect in this new situation? Arguably, we have to return to scripts that are most closely related. For the transition to remote learning during the COVID19 pandemic, the scripts most likely used were those of student expectations for typical teacher-student communication; to what extent are such expectations realistic or even relevant in such a unique situation?

While much of expectancy violations research is centered on nonverbal communication (Burgoon \& Hale, 1988), expectancy violations frameworks have been expanded to include verbal communication in instructional contexts, (e.g. Mottet, et al., 2006). At its core, the theory suggests that when expectations are violated, negative perceptions and outcomes result. In the context relevant to this study, expectancy violations could be anticipated to negatively impact student satisfaction and feelings of support, among other outcomes.

\section{INSTRUCTIONAL COMMUNICATION}

A plethora of variables are central to research in instructional communication. Regarding the teaching experiences of the authors during the transition to remote learning as well as based on the research above and instructional communication research, concepts of particular interest to this study are teacher communication and student satisfaction.

\section{TEACHER COMMUNICATION}

One area of importance in regard to teacher communication is teacher support. When teachers express interest in students' wellbeing, both academically and personally, a number of positive outcomes result. For example, Goldman and Goodboy (2014) found that teacher interest and an interactive teaching style result in emotional interest and support as well as a more positive classroom experience. Moreover, teacher messages, both verbal and nonverbal, that show support have both content and relational dimensions (Burleson, 2009). Regardless of whether content or relational dimensions are the message's focus, faculty confirming messages lead to more positive student outcomes than disconfirming messages, particularly in regard to leaner empowerment, student motivation, student motives to communicate, and relational distance between student and teacher (Garland and Violanti, 2020). Confirming messages indicate to the student that the teacher believes in and values the student (Ellis, 2000; Johnson \& LaBelle, 2020). With the pandemic in mind, teacher confirming messages would indicate the teacher and students are in it together, the teacher is available to assist the student academically and personally, the teacher understands the many challenges that the students are facing, and the teacher is willing to be flexible and adaptable to students' needs. Moreover, teachers serve as an integral source for aiding students in making sense of educational and life experiences (Titsworth, et al., 2010). In times of the COVID-19 pandemic, such guidance might include navigating a new course format, adjusting to altered content delivery methods, 
and communicating altered course expectations. While supportive messages and guidance are important to a typical educational experience, they are arguably even more critical in times of crisis, such as a pandemic.

Another area of importance in regard to teacher communication is teacher clarity. Teacher clarity refers to structural, verbal, and nonverbal teaching behaviors that lead to shared meaning about course-related content and processes (Chesebro \& McCroskey, 2001; Myers and Goodboy, 2014; Violanti, et al., 2018). Clarity of assignments, expectations, teaching format and delivery, teacher-student communication, and much more is necessary for an effective and desirable educational experience. Clarity at the start of the term leads to reduced student uncertainty and more realistic student expectations.

A third area of importance in regard to teacher communication is teacher consistency (Nelson, 2019). To date, consistency has centered on consistency on teacher communication and behaviors in a single instructional format. The 2020 pivot term, however, provided a unique opportunity to explore the importance of teacher consistency with a change in instructional modality. While students have individual preferences for the channel of teacher-student communication, communication through any channel is preferred to no or limited teacher-student communication, especially in times of uncertainty.

Teacher support, clarity, and consistency are integral to any instructional context, but it is anticipated that such concepts are central to the experiences of students during the COVID-19 pivot term. While such concepts are correlated with a number of student outcomes, one of particular interest during the pandemic is student satisfaction. Student satisfaction is a predictor for student retention (Murray \& Kennedy-Lightsey, 2013), critical to the success of educational institutions, and such predictors must be a focus of research.

\section{STUDENT SATISFACTION}

As students enter a class for the first time, they have expectations about their teachers, the course, and peer interaction. The expectations are based on past experiences in higher education, such as experiences with the instructor of record or with the anticipated format and delivery method, as well as information-seeking behaviors, like word-of-mouth or Rate My Professor. With this project in mind, student satisfaction is tied to instructor communication behaviors that assist students in meeting their goals and fulfilling their expectations. The behaviors include teacher support, clarity, and consistency, which have been positively correlated with student satisfaction (Goodboy \& Myers, 2007; Sidelinger, 2014; Sidelinger et al., 2015). Students are more satisfied when teachers are consistent in their communication behaviors and are in consistent communication with their students (Goodboy \& Myers, 2007). as well as when teachers are clear and engaged in their instruction (Johnson, 2013).
When the course format and delivery are abruptly shifted, as it was during the 2020 pivot term, students' expectations of the instructor, course format, content delivery are most likely violated. Such violations would lead to students judging instructor behaviors and course changes negatively (McPherson et al., 2003). Teacher communication that is context driven and follows the situational and relational rules should result in violation avoidance, as perceived by the student (Sidelinger, 2014). This would suggest that teacher clarity, consistency, and support would minimize the violations, or negative valence, that such an abrupt change in instruction produces because students' affect for a course and the teacher is correlated with student satisfaction (Goodboy, et al., 2009).

Taken together, the following research questions are posted.

RQ1: How do students describe their remote-learning experiences?

RQ2: How can we create smoother transitions when future instructional disruptions occur?

\section{METHODS}

\section{Participants}

Upon receiving human subjects review approval, students enrolled at two United States higher education institutions completed an online survey ${ }^{2}$. A total of 543 students participated in the study. Of those, 345 were female $(63.5 \%)$, 172 were male $(31.7 \%)$, two $(0.4 \%)$ were non-binary, and 24 (4.4\%) did not respond. While the majority were in their second year of college $(\mathrm{N}=298,54.9 \%), 75(13.8 \%)$ were first-year students, 99 (18.2\%) were third-year students, 41 (7.6\%) were fourth-year students, $10(1.8 \%)$ were fifth-year or beyond students, and $20(3.7 \%)$ did not respond. The mean age was 19.93 ( $\mathrm{sd}=2.58$ ) with a range from 18 to 52 .

\section{Procedures and Data}

For the purposes of this study, participants responded to four open-ended questions as part of the online survey completed between april and September 2020, which marked the pivot to remote learning at the end of one semester and continuation of remote learning at the beginning of the next semester. These questions addressed what they wished their instructor had done and had not done during the pivot to remote learning as well as advice they would offer to instructors and students if an instructional disruption should occur in the future. The responses resulted in 80 pages (17,301 words) of data used to address the two research questions. These data, using the phrase as the unit of analysis, were coded using thematic analysis (Owen, 1984). The first response was read and coded using phrases as the

\footnotetext{
${ }^{2}$ In the interest of transparency, the data reported here are part of a larger study on the pivot from face-to-face to remote teaching and learning. In addition to the open-ended data reported here, students also completed scales measuring the confirming and disconfirming messages used by their instructors, their current anxiety levels, and their perceived learning in the course on which they reported.
} 
TABLE 1 | Content analysis categories.

\begin{tabular}{|c|c|c|c|}
\hline Category & $\mathbf{N}$ & $\%$ & Exemplars \\
\hline Assignments & 117 & 13.31 & Didn't have random deadlines in the middle of the day [outside of regular class time], provided better notetaking guides \\
\hline Clarity & 80 & 9.10 & $\begin{array}{l}\text { Explained how this specific course would transition into virtual learning, be more specific about what he expects, spoken } \\
\text { more clearly }\end{array}$ \\
\hline Communication & 62 & 7.05 & Email me hundreds of emails during the night, been out of touch, answered [various] forms of communication \\
\hline Format & 486 & 55.29 & $\begin{array}{l}\text { Kept the discussion portion of class going, provided a more concrete online structure, understood that grading could have } \\
\text { been more lenient }\end{array}$ \\
\hline Interaction & 115 & 13.08 & $\begin{array}{l}\text { Spent so much time telling personal stories and not relating to the class, disregarded her students, figured we knew a lot of } \\
\text { things that are going down }\end{array}$ \\
\hline Other & 19 & 2.16 & [The teacher] getting sick, [instructor] more familiar with technology, hold other people more accountable \\
\hline
\end{tabular}

unit of analysis; each subsequent response either fit into an existing category, required an alteration to an existing category to better reflect the responses, or resulted in creating a new category to reflect the student's thought processes. A total of 879 phrases were placed into six categories. These themes, the categorical definitions, and the percentage of responses that address them are included in Table 1. After developing and categorizing the responses into the themes, those themes were connected back to the original research questions.

\section{RESULTS}

Generally speaking, students had a range of experiences during their pivot to remote learning. While these data focused specifically on the educational experiences, we would be remiss if we did not remind readers about the environmental changes so many of them also faced. Returning to their parents' homes from apartments and residence halls was difficult for many because the independence many had garnered at college was diminished in their parents' homes where they had no control over the space and other people who were living there. Additionally, some were returning to households where there were abusive parents or step-parents or had no homes to which to return at all. To continue paying rent on their apartments at school, many had to work at whatever jobs and whatever hours they could find; some also thought that online classes meant they could determine what they did and when, which was not the case in courses that chose to meet synchronously. Finally, being removed from campus meant that many lost their social connections-as they often say, texting is not the same as being there. The isolation, in conjunction with local stay-athome ordinances, had a definite impact on students' mental health. Using this as the backdrop for their comments, we first address their classroom experiences.

While a small number of students (less than $10 \%$ of those participating) reported that their transition to remote learning was smooth and there was nothing they wished the instructor had done or had not done, the vast majority of participants reported on frustrations with remote learning. From their composite responses, we present the story of Alex, a second-year college student returning home to finish the first 2020 pandemic term remotely.
Alex wakes up in the morning prepared to spend the day in the bedroom going to class, doing homework, and trying to connect with group members to finish a project. A neighbor is having a tree cut down and the noise makes it difficult to concentrate. Logging on to the campus learning management system (LMS), Alex believes a new assignment has been posted for one of the classes and the teacher has decided to have a spontaneous Zoom session today during what would have been class time. Alex thinks, "Good thing I did not pick up that extra shift at work." Before logging on to the synchronous class system, Alex checks email and finds over a page of emails, all of which have been generated in the LMS and go along with the five courses Alex is enrolled in. Because of the tags added to the subject line, it is impossible to easily determine which ones go with which classes and read them all together or determine which ones are most important, so Alex closes email and decides to wait for more time to go through all of that. Time to check Facebook, Twitter, and Slack because two instructors have decided they want to use those channels for communicating with students. The instructions for an assignment have been posted, but they seem vague and unclear as to how it will be graded. Alex makes a note to ask about this in class, especially since there is no due date on the assignment sheet. The phone starts dinging with notifications from the various GroupMes that the students have set up for each class. People are complaining about how confusing all of these assignments are and wondering why some teachers have given up completely-no communication, just a bunch of assignments on the LMS-and others are so overwhelmed that they are inundating students with a new email for every little thing. Time for class. Alex logs onto the platform and finds out that the instructor is having difficulty getting the screen share to work so they are going to have to take notes without benefit of the slide deck. Rather than having a class discussion, they end up in breakout rooms to work through the course content themselves. Alex is thinking, "If I knew the answer to these questions, there would be no reason to come to class and I could go back to bed or go to work and earn money." A second synchronous class is no better and the instructor left no time to ask the questions Alex had planned to find out more about the vague assignment. The day ends with a series of excuses for why others cannot work on their group assignments. Off to bed so that Alex can jump back on the hamster wheel to run for another day without feeling any sense of accomplishment.

Alex's story is not unique and resembles stories heard from many students. The elements align with the categories found in 
the students' responses and also address a component not heard specifically in the responses-the issues associated with leaving the campus environment and living in someone else's home where the student controls neither the environment nor the time zone in which it is located.

\section{Assignments}

Assignments were defined as ways in which course materials, learning activities, and assessments are designed, or redesigned during remote learning. In this category, students talked about making aids available to help them with the learning process such as providing "better notetaking guides" and reinforcing "the main points so we know what we are to get out of each lesson." Others focused on the time associated with each class wondering why faculty "would make what was supposed to be a 50-min exam take $3 \mathrm{~h}$ " because "It interfered with the classes I had after." In terms of learning materials, students recognized that they were missing out on the oral nature of being in a physical classroom as the student sought "more videos for kids who struggle to learn by reading." One student enrolled in a public speaking course talked about the irony of how the speech assignments changed when the delivery mode changed.

I also feel that completing what is essentially a course designed to teach you how to communicate in a "prepared" but extemporaneous way is made increasingly difficult by the addition of video recording requirements--live presentations on zoom would seem to be a comprable experience vs. in person presenting; however given the circumstances, one feels that the standards should be adjusted to reflect the additional difficulties imposed on students by the video recording requirement.

Other comments were similar to what is seen in any semester: fewer assignments, lighter workload, more extra credit opportunities, and more time to complete assignments.

\section{Clarity}

Regardless of instructional modality, providing students with understandable and meaningful messages is a hallmark of effective teaching. Responses fitting into the clarity category emphasized the extent to which the messages used to communicate about the course, assignments, technology, and expectations are understandable, direct, and uncomplicated. Many of the comments in this category focused on organization, both of the instructor and the course site. For example, students wanted the instructor "to make it more clear where assignments were" and "be more explicit on due dates." Students also indicated a need for clearer instructions about how to use the LMS as well as any technologies that the instructor was going to use: "given more guidance with the types of technology we would be using" and "given more instruction with tech." Even though some of these students had been using the same LMS prior to coming to college, they still sought explicit instructions about how each individual instructor would be using it. Finally, the students highlighted the need for better organization and clearer assignment instructions because the instructor "sent out so many assignments with little explanation on how to get credit for them." As one student lamented, "been more detailed. I learned less when we went online;" clarity was a key component in the remote learning environment.

\section{Communication}

As administrators encouraged faculty to overcommunicate on these two campuses, students gave the strategy mixed reviews. For example, some indicated faculty "sent a billion emails a day, when they could keep it concise-I know it was a hard time for everyone, but come on" and "communicated more." There was general agreement that email was the best communication tool, but less agreement about whether it should be every time something new is posted, daily, or weekly. While instructors were more apt to send out the messages they wanted students to have, they also seemed to be having a difficult time keeping up with the additional email being generated by students and their concerns. For example, many indicated the faculty member "responded to emails so slowly regarding questions about classes" or should give "more comments to my work." This student summed up the communication category and its connection to other areas well:

sent out more announcements to keep us in the loop. For us students, we found out about classes going online during spring break, but my class did not even get notified about what was expected of us until the second full week of online classes. We never had set zoom meetings, we were just expected to work on our Google Drives with our groups and that was our attendance. We were also able to participate in the live chat, but I wish we would have had at least one meeting to go over everything and what was expected so we were less confused and better informed.

While organizational research has indicated employees seem to continually seek more information and more communication because they have positive effects on satisfaction (Popescu \& Crenicean, 2016; Ghorbanzadeh et al., 2020), the same was not true in this case for students.

\section{Format}

The largest category of comments had to do with course format, the ways in which the course is structured or restructured, including the use of technology and grading. There was a repetition to these comments that addressed a few very specific areas. The first had to do with grading. Many students indicated a need to be more lenient with grading, especially regarding group assignments. While few provided reasons for their grading leniency requests, one student indicated "been more lenient with grades considering we didn't know how to work many of the websites used."

The second set of comments had to do with the way the course content was delivered. As is often the case, there was disagreement about whether there should be more synchronous learning or more asynchronous learning. Some students wanted the freedom that goes along with asynchronous learning (drop "zoom calls altogether. I had to pick up a job and it was hard keeping a schedule around strict 
class times" and "understood that some of us lived in different time zones and meeting synchronously was difficult") and others sought the structure that goes along with synchronous learning ("made more requirements of the class in order to force me to stay grounded" and "give us synchronous meeting times"). Students also wanted instructors to start "the class [at] a slower pace so student $[\mathrm{s}]$ could adjust to the new learning style and then speed things up." In addition to the transition, students talked about how the course design changed, and it was not always for the better, "The class was a discussion class so more assignments were assigned to make up for the lack of discussion that was not present." Lastly, students were concerned about learning and timing. One student indicated that the instructor should post "videos more gradually as opposed to days without anything then all of a sudden we had like five at one time." Some of these comments also connected back to issues of clarity and consistency.

The last set of comments had to do with technology. When classes met synchronously, students appreciated it when instructors "taught slower over Zoom." The lag time and fatigue associated with long periods of time online was evident as students indicated that they needed more time to process the course content when it was online. Other students talked about specific aspects of the technology, such as having "better equipment to show the math problems she was working out, something other than just pen and paper" or "had the ability to write on a white board or an application to write with and share with the class." In a quick pivot to remote teaching and learning, these additional tools may not have been readily available or quickly learned. It was clear that students had negative impressions of working in groups in the technology-mediated environment. Some sought more time together in smaller groups ("done more interactive learning in breakout rooms rather than just go through powerpoints and notes") and others found the time to be wasted due to lack of structure and preparedness ("included more time to learn rather than just large zoom lectures" and "don't put kids into breakout rooms for too long or they will end up silent eventually"). Group work was summed up as "it made it more difficult to learn because nobody ever wanted to work together." With respect to technology, the most controversial aspect of meeting synchronously revolved around whether people should be required to have their cameras on and be visible. Students who specifically addressed this topic worried that "having the camera on. If felt like it was an invasion of privacy"; yet, other students saw these synchronous meetings as an opportunity to reconnect with the friends they had made and felt both audio and visual was necessary to make those connections (should "require zoom cameras to be on").

\section{Interaction}

Interaction was defined as messages that address the relational and identity communication goals (Clark \& Delia, 1979); involves students' perceptions of themselves, their instructors, and the ways they connect with, or disconnect from, their instructor and classmates. Some specific strategies for creating interaction opportunities included "had more Zoom meetings so we could still engage with each other" and "connect fellow students to each other more [in groups or the class as a whole]." Additionally, there was a consistent call for less of the negativity associated with the situation ([should not have] "focused on all the negatives" and "been so negative about the transition") and more encouragement and positivity ("encouraged students to keep going"). In a time when mental health and physical health were both deteriorating, students wanted instructors to "check on us more." While instructors are not health professionals, they would be able to help students access the resources they needed. Another type of disconnection students felt was that they were going this alone instead of being in it with their instructor ("left us in the dirt," "assumed the transition would be easy for everyone," and "assumed we know what we were doing"). On campuses where the administrative message and in a society focused on "we're all in this together," feeling disconnected from an instructor seemed to be heightened.

\section{DISCUSSION}

\section{Uncertainty Management}

Over the course of a term, the need for uncertainty management diminishes as students develop trusting relationships with other students and the instructor; they also reduce their uncertainty levels as they find themselves being successful or learning from their mistakes. The first assignment or exam in a course tends to have the lowest average score as students learn the instructors' assessment strategy and how to best adapt their studying to succeed on the assessment. When classes moved from traditional face-to-face environments to the remote learning environment, students found themselves starting the uncertainty management process from the beginning; it was as if they had been picked up out of their current course and transported to a completely new term halfway through. They did not have the time or energy for the socialization processes that would help them learn how to navigate the situation and increase their efficacy to the point that it should have been halfway or more through the term. Additionally, they did not have scripts from past courses on which to draw to help them traverse the unexpected path to the end-of-term finish line.

As their uncertainty about what was happening in their classes as well as in their families and lives outside of school increased, their need to reduce uncertainty in at least one of those areas became critical to developing a sense of balance. Nothing seemed certain regarding the pandemic, so students looked to instructors and peers to help quell their anxiety. The best way to alleviate their fears was to seek out familiarity in their courses.

As we can see from Alex's story and the themes contained in Table 1, uncertainty and the need to reduce uncertainty remains prevalent among the students who found themselves in the unfamiliar realm of remote learning. Clarity, communication, consistent format, and interaction all contribute to feelings of enhanced or reduced uncertainty. When instructors were able to continue providing concrete directions for assignments, schedules with specific due dates that allow students to plan out the remainder of the term, and explicit, and clear instructions about how to use the new technologies (LMS, video conferencing 
app or software, and electronic submission of assignments), students' uncertainty levels were lessened. Communication and interaction were additional ways to help students manage their heightened uncertainty. For example, staying in contact with students, remembering to take time to ask how they were doing, and maintaining the relationships built earlier in the term are all effective ways to help students manage their uncertainty. Additionally, providing consistent messages about the course, reminders about their responsibilities, and encouragement that instructors believe in their students are also effective management strategies. Instructors who walked away from their students amid their own uncertainties found themselves with a class full of students who were dissatisfied and experiencing increased uncertainty. When students are unable to reduce uncertainty using their familiarity with the course, they turn to alternatives to help them fill in the gaps. Some students may turn to networking apps, such as GroupMe, to have other students help them fill in the gaps; others may turn to friends who are also battling uncertainty. Either way, the outcome tends to be heightened anxiety because it acts as a contagious virus in the same way that the number of Covid-19 cases increased exponentially each day.

\section{Expectations}

While expectations were not as prevalent in Alex's story, they are still an underlying component of students' experiences. When people's positive expectations are met or exceeded, they attribute a more positive valence to the situation and relationship. Students expected instructors to go outside of their instructional roles and help them with all aspects of the remote learning environment. In many ways, students expected instructors to behave in ways the students found almost impossible. For example, students expected instructors to have already thought about the possibility that this would happen and have planned for it, knowing how they would make adjustments to the course and how to teach students to operate the technology. In reality, those expectations were idealistic rather than realistic as some instructors were learning the LMS and communication technology alongside their students.

Based upon the student responses, it appears that instructors also had unrealistic expectations regarding students' behaviors. For example, instructors expected students to be able to devote the same level of time and attention to each course as they had been when they were coming to a physical class on campus without a health pandemic. In reality, students found themselves having to split their attention among their family (and potential caregiving responsibilities for younger siblings or older family members), their personal health, their classes, and potentially a job or internship. When students did not respond or behave as expected, they formed a negative judgment about students as uncaring or uncommitted and altered their own communication accordingly. When faculty withdrew from, or altered, the relationships with their students, that strengthened students' negative valences and they cycle continued until the relationship developed in the face-to-face classroom was only a small remnant of what had existed only a few weeks earlier.

\section{LIMITATIONS AND FUTURE RESEARCH}

The data for this study came from two United States Universities, one of which is considered a high research institution and one of which is considered a comprehensive teaching institution. The data generated from the two types of institutions was remarkably similar-students crave the same types of instructional settings as well as interactions with their peers and instructors. While it mirrors studies from across the United States, parallel data from around the world are needed to determine whether there are potentially geographical and/or cultural differences regarding remote learning.

These data also reflect the very early stages of remote learning. As many institutions enter their third term and beyond, these same questions should be asked to see how students' perceptions have changed as well as the sensemaking processes they are using to attach meaning to what is a new learning environment for most instructors and students. Other considerations would include how instructors and students have enhanced their preparation for remote learning. To what extent do these remote learning environments now more closely align with the synchronous and asynchronous online learning environments that were purposefully created prior to the health pandemic? Are students developing the self-determination, time management, and other skills prevalent in those who choose online learning? Are faculty moving beyond taking the face-to-face format and placing it in a mediated context, (i.e. moving away from full class period recorded lectures in favor of shorter videos that are chunked according to topics)? What are institutions doing to onboard their students and faculty for the remote learning environment?

A final limitation is that we did not collect specific demographic data, which may impact how students responded in this pivot to remote learning. Demographics that would be helpful to connect with students' experiences include where they attended their remote classes, (e.g. space where they were the only one living, space they shared with other students, space they shared with their family, emergency residence hall exception, their cars where they could use unlimited cellular data or log into a retail establishment's free $\mathrm{Wi}$-Fi), what other responsibilities they had, (e.g. work, family, caregiver), and their health (both mental and physical). Being able to connect students' situations with their experiences would help faculty and administrators better plan for the future of education.

\section{Implications}

Taken together, several lessons can be learned from the experiences of students based on the themes presented. When it comes to preparing assignments for remote learning, teachers should be careful of assumptions. For example, not all students are familiar and experienced with submitting assignments through the learning management systems. Detailed instructions for submission should be provided in addition to the due date, grading rubric, technology troubleshooting tips, and additional resources, such as tutoring or writing centers. Students would also likely appreciate a sample submission demonstrating 
the elements of a successful submission, which would likely help teachers avoid the "how many pages" and formatting questions.

When it comes to clarity and communication, teachers should post, or otherwise provide, an updated syllabus to clarify new processes, procedures, and expectations. The updated syllabus should clarify important logistical information, such as how and when remote office hours will be held, a timeframe for when students can expect to hear back from the instructor-we recommend a 24 to $48 \mathrm{~h}$ turnaround; and when students should check for emails and other course announcements. In addition to clarity, teachers should be intentional in their consistency. For example, teachers should aim to send emails and/or post announcements at consistent times and keep deadlines consistent. Students become very frustrated when faculty create an assignment deadline of 5:00 pm on Friday one week and midnight Sunday the next week, especially for a class that meets on Tuesday and Thursday. Consistency also minimizes the number of student emails regarding deadlines.

Lastly, teachers need to focus on the human element of teaching. Touch base with students individually when possible to better understand their unique needs and challenges. This allows instructors to make more informed decisions about course requirements, such as whether to require audio or video student participation. It also provides faculty with an opportunity to adapt students' experiences into creative, relevant course, or concept, examples. Instructors should also let students know that they empathize with them and support them as they work to overcome the challenges they are facing by providing resources for mental health, food and housing insecurity, and the like when possible.

As is often the case in instructional settings, trying to address the needs of all students creates dialectical tensions as there are students, usually in the same class, who want completely different approaches. For example, some students wanted all of the assignments at once so they could work at their own pace and others wanted them spaced out as they had been on the original syllabus; some wanted to meet synchronously and others wanted everything to be asynchronous; some wanted the instructor to maintain the rigorous standards that had been in place and others

\section{REFERENCES}

Active Minds (2020). COVID-19 impact on college student mental health. Available at: https:/www.activeminds.org/wp-content/uploads/2020/04/ Student-Survey-Infographic.pdf.

Aucejo, E. M., French, J., Araya, M. P. U., and Zafar, B. (2020). The impact of COVID-19 on student experiences and expectations: evidence from a survey. J. Publ. Econ. 191, 1-15. doi:10.1016/j.jpubeco.2020.104271

Berger, C. R., and Calabrese, R. J. (1975). Some explorations in initial interaction and beyond: toward a developmental theory of interpersonal communication. Hum. Commun. Res. 1 (2), 99-112. doi:10.1111/j.1468-2958.1975.tb00258.x

Brashers, D. E. (2001). Communication and uncertainty management. J. Commun. 51 (3), 477-497. doi:10.1111/j.1460-2466.2001.tb02892.x

Burgoon, J. K., and Hale, J. L. (1988). Nonverbal expectancy violations: model elaboration and application to immediacy behaviors. Commun. Monogr. 55 (1), 58-90. doi:10.1080/03637758809376158 wanted significantly more leniency/fewer assignments/more extra credit; some sought connections with others through the use of audio and video and others saw this as an invasion of privacy. In situations like this, the instructor is left to determine whether meeting the needs of the middle (those within one to two standard deviations of the norm) is the best approach or whether meeting the needs of all students from high to low performers is the best approach. Ideally, we would meet the needs of all learners; in a time-crunched pivot to remote learning, the design and preparation work necessary to accomplish those goals was impossible. Many faculty and students alike did the best they could, especially given the personal and professional uncertainty as well as the various stakeholders' expectations. Moving forward, we each have a responsibility to improve the teaching and learning environment in ways that promote inclusion and equity for all.

\section{DATA AVAILABILITY STATEMENT}

The raw data supporting the conclusion of this article will be made available by the authors, without undue reservation.

\section{ETHICS STATEMENT}

The studies involving human participants were reviewed and approved by the University of Tennessee Knoxville IRB. Written informed consent for participation was not required for this study in accordance with the national legislation and the institutional requirements.

\section{AUTHOR CONTRIBUTIONS}

All authors listed have made a substantial, direct and intellectual contribution to the work, and approved it for publication. Authorship order is alphabetical. Both authors contributed equally.

Burleson, B. R. (2009). Understanding the outcomes of supportive communication: a dual-process approach. J. Soc. Pers. Relat. 26 (1), 21-38. doi:10.1177/ 0265407509105519

Chesebro, J. L., and McCroskey, J. C. (2001). The relationship of teacher clarity and immediacy with student state receiver apprehension, affect, and cognitive learning. Commun. Educ. 50 (1), 59-68. doi:10.1080/ 03634520109379232

Clark, R. A., and Delia, J. G. (1979). Topoi and rhetorical competence. Q. J. Speech. 65, 187-206. doi:10.1080/00335637909383470

Ellis, K. (2000). Perceived teacher confirmation: the development and validation of an instrument and two studies of the relationship to cognitive and affective learning. Hum. Commun. Res. 26 (2), 264-291. doi:10.1111/j.1468-2958.2000. tb00758.x

Garland, M. E., and Violanti, M. T. (2020). Open communication may not be promotive communication: Faculty messages and learner outcomes [Top Paper Panel; virtual presentation]. in International Communication Association Annual Conference, May 21-26, Gold Coast, Australia 
Ghorbanzadeh, M., Mahmoudi, H., Sirati Nir, M., and Khoshnevis, M. A. (2020). Does caring for trauma patients admitted to emergency departments need advanced communication skills? A quasi-experimental study of nurses' communication audit. Trauma Mon. 25 (2), 71-77. doi:10.30491/TM.2020. 213517.1014

Goldman, Z. W., and Goodboy, A. K. (2014). Making students feel better: examining the relationships between teacher confirmation and college students' emotional outcomes. Commun. Educ. 63 (3), 259-277. doi:10. 1080/03634523.2014.920091

Goldsmith, D. J. (2001). A normative approach to the study of uncertainty and communication. J. Commun. 51 (3), 514-533. doi:10.1111/j.1460-2466.2001. tb02894.x

Goodboy, A. K., Martin, M. M., and Bolkan, S. (2009). The development and validation of the student communication satisfaction scale. Commun. Educ. 58 (3), 372-396. doi:10.1080/03634520902755441

Goodboy, A. K., and Myers, S. A. (2007). Student communication satisfaction, similarity, and liking as a function of attributional confidence. Ohio Communication Journal 45, 1-12.

Hanson, T. L., Hallmark, J. R., Mallard, J., and Griego, G. (2014). Reducing student uncertainty through discipline specific and non-discipline specific sections of freshman seminar. Tex. Speech Commun. J. 38 (1), 112-134.

Houser, M. L. (2005). Are we violating their expectations? Instructor communication expectations of traditional and nontraditional students. Commun. Q. 53 (2), 213-228. doi:10.1080/01463370500090332

Johnson, D. I. (2013). Student in-class texting behavior: associations with instructor clarity and classroom relationships. Commun. Res. Rep. 30 (1), 57-62. doi:10.1080/08824096.2012.723645

Johnson, Z. D., and LaBelle, S. (2020). Confirmation in the college classroom: the connections between teacher's use of confirming messages and student's own communicative behaviors. Commun. Res. Rep. 37 (4), 172-181. doi:10.1080/ 08824096.2020.1800449

McPherson, M. B., Kearney, P., and Plax, T. G. (2003). The dark side of instruction: teacher anger as classroom violations. Commun. Res. 31 (1), 76-90. doi:10.1080/ 00909880305376

Mottet, T. P., Perker-Raley, J., Cunningham, C., Beebe, S. A., and Raffeld, P. C. (2006). Testing the neutralizing effect of instructor immediacy on student course workload expectancy violations and tolerance for instructor unavailability. Commun. Educ. 55 (2), 147-166. doi:10.1080/ 03634520600565886

Murray, C. L., and Kennedy-Lightsey, C. D. (2013). Should I stay or go?: student identity gaps, feelings and intent to leave. Commun. Res. Rep. 30 (2), 96-105. doi:10.1080/08824096.2012.762894

Myers, S. A., and Goodboy, A. K. (2014). Members of COMM 600.College student learning, motivation, and satisfaction as a function of effective instructor communication behaviors. South. Commun. J. 79 (1), 14-26. doi:10.1080/ 1041794X.2013.815266

Nelson, S. (2019). Care, consistency, and content the 3Cs of classroom management in the middle school English language arts classroom. AMLE (American Middle Level Education) Magazine 7 (3), 13-16.

Neuliep, J. W., and Grohskopf, E. L. (2000). Uncertainty reduction and communication satisfaction during initial interaction: an initial test and replication of a new axiom. Commun. Rep. 13 (2), 67-77. doi:10.1080/08934210009367726

Owen, W. F. (1984). Interpretive themes in relational communication. Q. J. Speech. 70, 274-287. doi:10.1080/00335638409383697

Popescu, M., and Crenicean, L. (2016). Organizational communication audit-plus value in business. Quality-Access to Success Journal 17 (3), 173-181.

Prisbell, M. (1990). Classroom communication satisfaction, teacher uncertainty and course certainty over time. Commun. Res. Rep. 7 (1), 20-24. doi:10.1080/ 08824099009359849

Sidelinger, R. J., Nyests, M. C., Madlock, P. E., Pollak, J., and Wilkinson, J. (2015). Instructor privacy management in the classroom: exploring instructors' ineffective communication and student communication satisfaction. Commun. Stud. 66 (5), 569-589. doi:10.1080/10510974.2015.1034875

Sidelinger, R. J. (2014). Using relevant humor to moderate inappropriate conversations: maintaining student communication satisfaction in the classroom. Commun. Res. Rep. 31 (3), 292-301. doi:10.1080/08824096.2014.924339

The Chronicle of Higher Education (2020). Data points: 2020-2021 almanac data highlights. The Chronicle of Higher Education July, 13.

Titsworth, S., Quinlan, M. M., and Mazer, J. P. (2010). Emotion in teaching and learning: development and validation of the classroom emotions scale. Commun. Educ. 59 (4), 431-452. doi:10.1080/03634521003746156

Violanti, M. T. (2020). Avoiding expectancy violations: Starting with course content on day 1. Communication Teacher. doi:10.1080/17404622.2020. 1862268

Violanti, M. T., Kelly, S. E., Garland, M. E., and Christen, S. (2018). Instructor clarity, humor, immediacy, and student learning: replication and extension. Commun. Stud. 69 (3), 251-262 . doi:10.1080/10510974.2018.1466718

Conflict of Interest: The authors declare that the research was conducted in the absence of any commercial or financial relationships that could be construed as a potential conflict of interest.

Copyright (C) 2021 Garland and Violanti. This is an open-access article distributed under the terms of the Creative Commons Attribution License (CC BY). The use, distribution or reproduction in other forums is permitted, provided the original author(s) and the copyright owner(s) are credited and that the original publication in this journal is cited, in accordance with accepted academic practice. No use, distribution or reproduction is permitted which does not comply with these terms. 